\title{
Focal palmoplantar and gingival keratoderma
}

INSERM

\section{Source}

INSERM. (1999). Orphanet: an online rare disease and orphan drug data base. Focal palmoplantar and gingival keratoderma. ORPHA:2200

Focal palmoplantar and ging ival keratoderma is a very rare form of focal palmoplantar keratoderma characterized by painful circumscribed hyperkeratotic lesions on weightbearing areas of soles, moderate focal hyperkeratosis of palmar pressure-related areas and an asymptomatic leukokeratosis confined to labial- and lingual- attached gingiva. Additional occasional features may include hyperhidrosis, follicular keratosis and extended oral mucosa involvement. 